\title{
Torque Control Strategy for Induction Motor Based On Fuzzy System
}

\author{
Vaisakh. T \\ Post Graduate, Power Electronics and Drives
}

\begin{abstract}
The paper provides a torque management strategy for induction motor drives. The strategy makes use of fuzzy primarily based change pattern for the device switches for conversion of the DC to AC. The device could be a standard six switch device topology. Out of the six switches 2 are going to be condensors and alternative switches are going to be IGBTs. The reduction within the range of switch can cut back the losses. Steady state operation of the induction motor is maintained by PI and symbolic logic controllers
\end{abstract}

Keywords: DTC, four FSTPI/SSTPI, torque management method

\section{Introduction}

The major benefits of DTC theme introduced within the middle of 80's result in additional researches that improved the initial DTC strategy yielding superior performance.

The areas of focus were in the main torsion ripple and shift frequency. To search out an answer for mentioned issues, area vector modulation is incorporated. Along side four switch VSI, the disadvantage of this being solely complexness in implementing the theme. The projected scheme is equipped for ripple reduction in torsion. The steady state oscillations and unwanted forced oscillations will be eliminated by the designed PI controllers

\section{Circuit Diagram Description}

The AC input is fed to a 3 phase diode bridge that produces a DC output. The DC is additional regenerate to $\mathrm{AC}$ by a four switch three phase electrical converter topology before feeding to the induction motor. The fuzzy controller makes it doable to manage the triggering of the inverter aspect switches to supply the specified output Vector management strategy is wide employed in the implementation of 4 switch three phase electrical converter. In the six switch topology the active vectors gift were six that is currently fastidiously curtail to four within the planned topology. The PWM signal is applied to the switches to get the specified shift pattern and thus the specified output. to create this doable we tend to use the house vector pulse breadth modulation. The electrical converter consists of two condensers and four switches. The individual voltage across every condenser is $\mathrm{Vc} 1$ and $\mathrm{Vc} 2$.

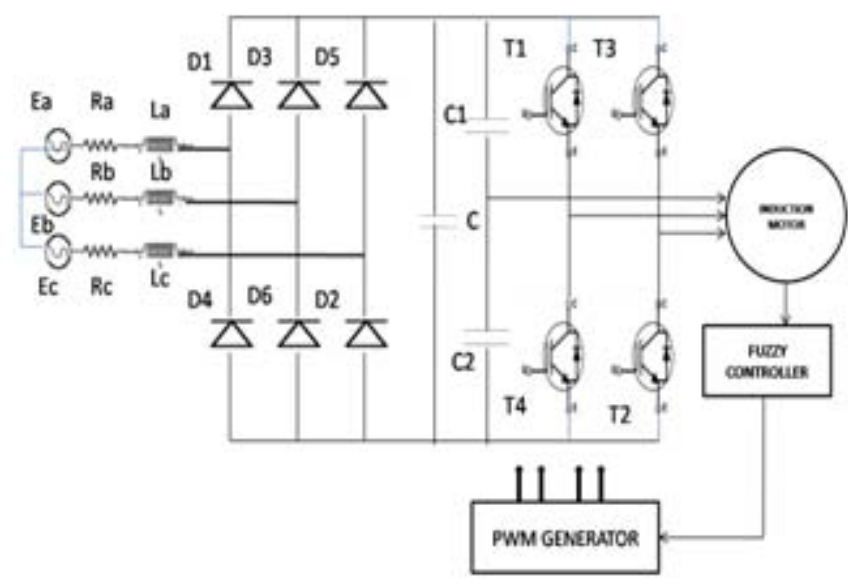

$\mathrm{Vdc}=\mathrm{Vc} 1+\mathrm{Vc} 2$

In order to change the switches a tiny low dead time is given between the switches of the higher and lower switches to make sure no accidental short circuits. Scheme of scalar modulation that makes use of part voltages for the assessment and calculation of shift frequency is created use I this topology because the implementation is fairly simple..

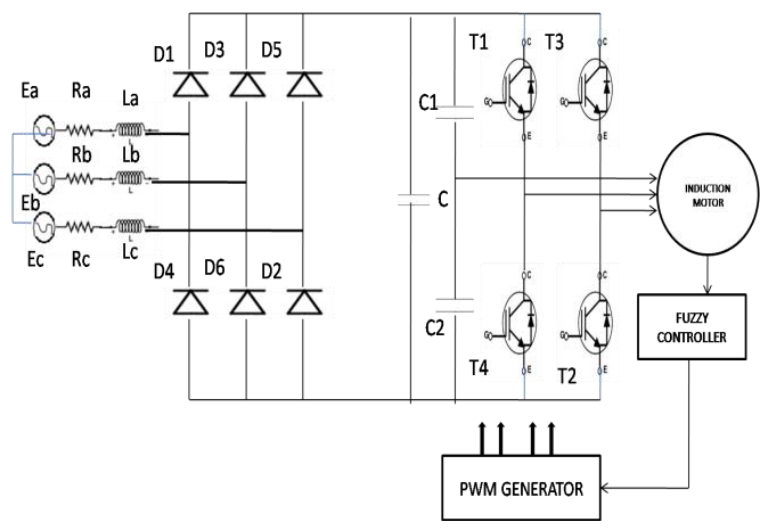




\section{International Journal of Science and Research (IJSR) \\ ISSN (Online): 2319-7064}

Index Copernicus Value (2013): 6.14 | Impact Factor (2014): 5.611

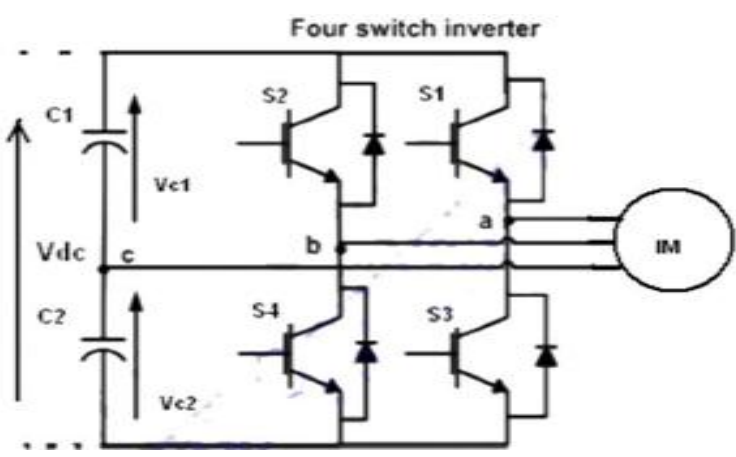

\section{Block Diagram}

The projected electrical converter is employed to regulate the induction motor. diagram includes input from power provide, PIC drive circuit, management algorithmic program and individual shifting circuit at the input aspect $\mathrm{s}$ well as the load facet.

\section{Input supply.}

The input given is associate degree $\mathrm{AC}$ offer to a diode bridge rectifier. The DC output from the rectifier is fed to the projected electrical converter. The output from the feedback loop is fed to the electrical converter that regulated the switches in step with the load demand. The input to IC and drive circuit is inevitably given from $+5 \mathrm{~V}$ and $+12 \mathrm{~V} \mathrm{DC}$ provide

\section{Rectifier}

A diode bridge rectifier circuit provides satisfactory performance for our application. Around ninetieth of rms value of input are availed at the output of the rectifier. The ripples offer at the output of the rectifier circuit as a result of the operation of the diode is fittingly filtered by the employment of electrical device.

\section{Torque Calculator}

A simple PI controller is employed for the aim of torsion estimation. Speed error between reference speed and actual speed is obtained and torsion is calculated. The calculated torsion is fed to the fuzzy controller. we have a tendency to keep the mechanical device flux at a set price and vary the mechanical device angle.

\section{Flux Calculator}

Fuzzy logic controller is once more answerable for the operation of flux estimation. The input from PI controller as current part is created use to regulate speed. The output from the formal logic controller is employed to seem up the shift table of area vector pulse dimension modulation.

Induction Motor- Motors square measure most generally used for industrial application square measure induction motors. The foremost versatile feature regarding induction motor is its characteristic constant speed fro no load to full load. The speed management mechanisms square measure typically enforced in DC motors as induction motors square measure less flexible for speed management. The rotor rotates within the external field created by the mechanical device and also the electricity is born-again to energy. that's why it's known as a rotating electrical device.

\section{Fuzzy Controller}

A fuzzy controller is introduced within the system to assess the correlation between the prevailing condition and also the output. This relation is checked employing a IF-THEN rule that is common in fuzzy abstract thought systems. The represented condition is related to the conclusion mistreatment the rule. the previous half chiefly refers to the condition whereas the latter describes the output or the conclusion.

\section{Implication Rule}

The output and input square measure correlative by the higher than mentioned rule. The essential sense of formal logic is created in use here.
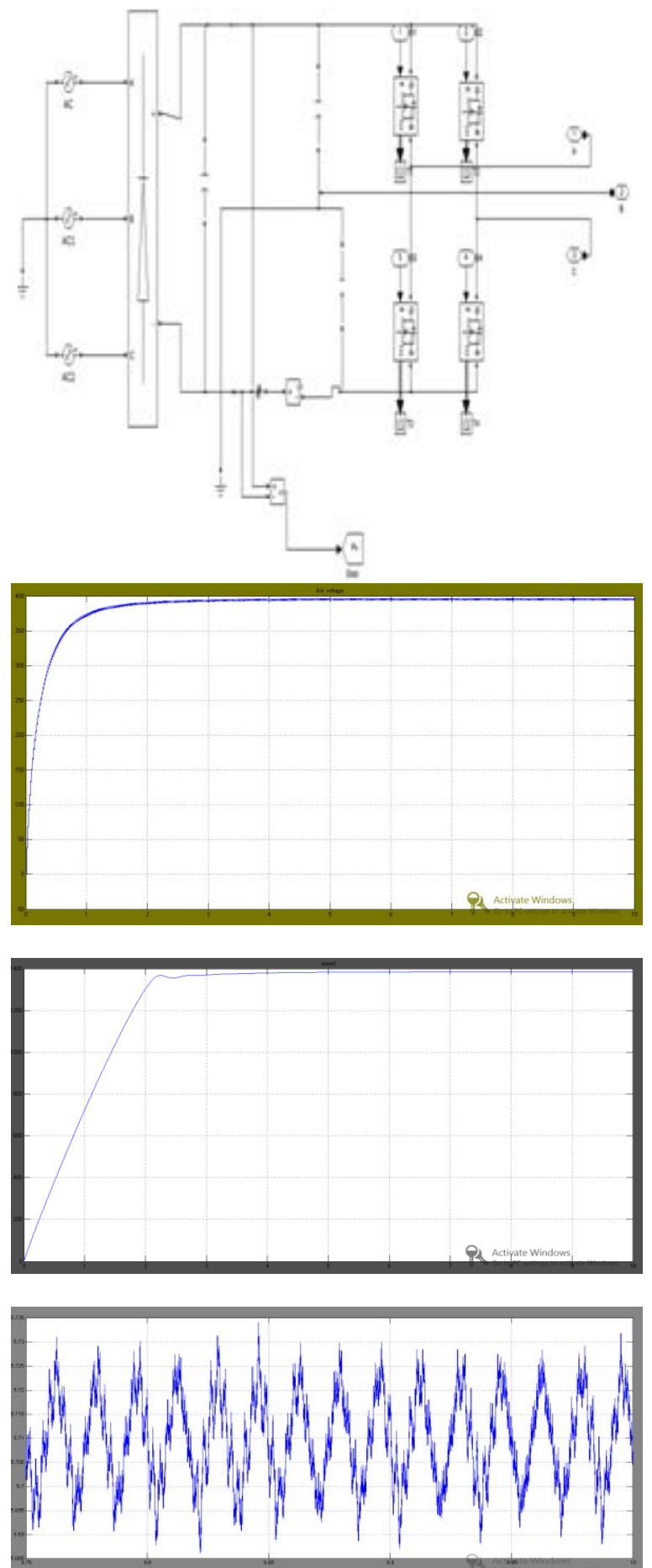


\section{International Journal of Science and Research (IJSR)}

ISSN (Online): 2319-7064

Index Copernicus Value (2013): 6.14 | Impact Factor (2014): 5.611

\section{Experimental Result}

The circuit was developed and the analysis of the proposed scheme using MATLAB obtained the results below.

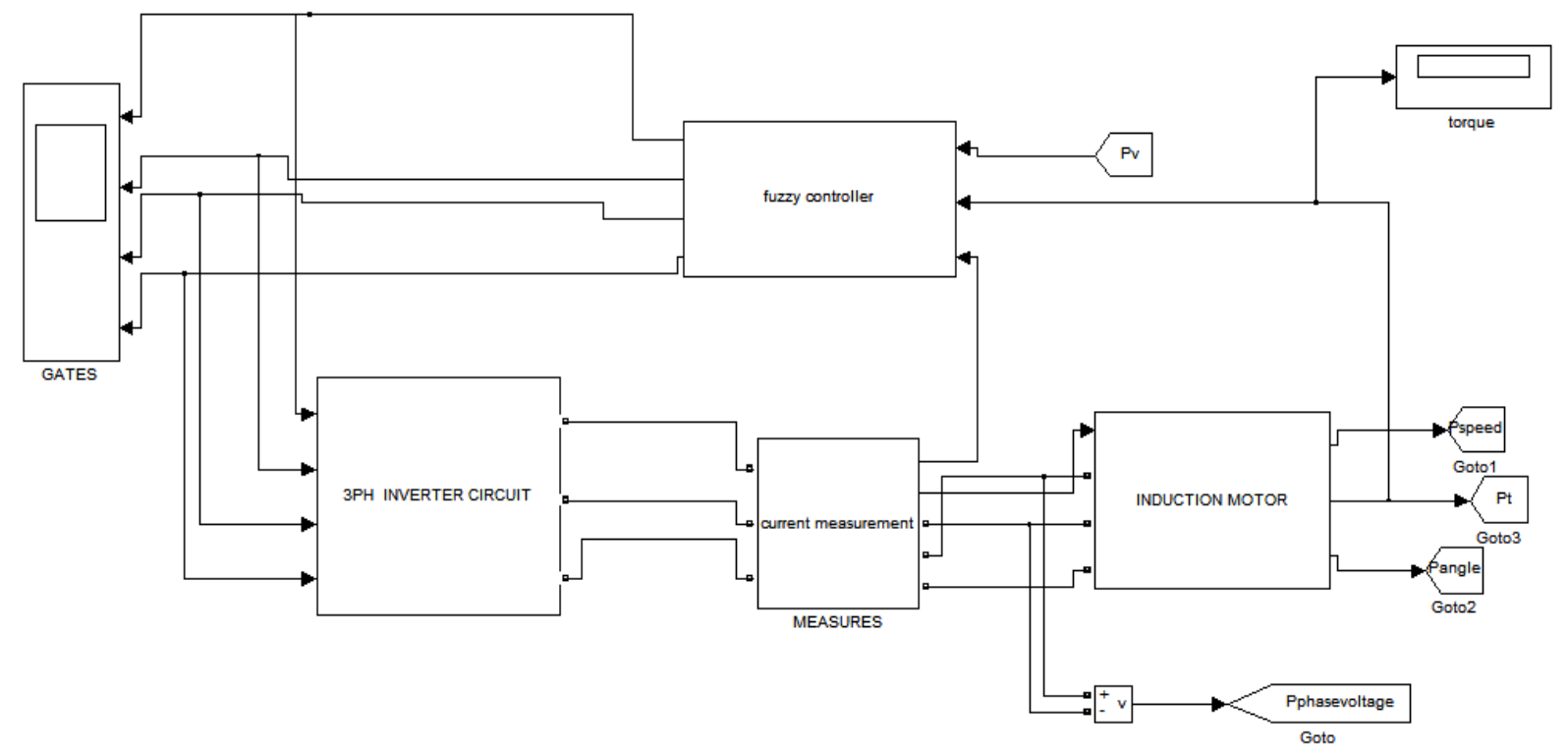

\section{Conclusion}

A simple but efficient method to control the torque ripple in induction motor is presented in the paper. The strategic selection of the control signal of inverter enables us to have direct control over motor variables.

\section{References}

[1] Chung-Ming Young, Neng-Yi Chu, Neng-Yi Chu, Liang-Rui Chen, Yu-Chih Hsiao, \& Chia-Zer Li, "A Single phase multilevel inverter with Battery Balancing",IEEE Transactions on Industrial Electronics, Vol 60, No 5 May 2013.

[2] B. Y. Chen and Y. S. Lai, "New digital-controlled technique for battery charger with constant current and voltage control without current feedback" , IEEE Transactions on Industrial Electronics, Vol. 59, no. 3, pp. 1545-1553, Mar. 2012.

[3] Pablo Lezana, Jose Rodriguez, and Diego A. Oyarzun "Cascaded Multilevel Inverter With Regeneration Capability and Reduced Number of Switches" , IEEE Transactions on Industrial Electronics, Vol. 55, NO. 3, Mar. 2008.

[4] Leon M. Tolbert, Burak Ozpineci, and John N. Chiasson, "A Five-Level Three-Phase Hybrid Cascade Multilevel Inverter Using a Single DC Source for a PM Synchronous Motor Drive", IEEE Applied Power Electronics Conference, APEC 2007.

[5] K.R.Padiyar, , "HVDC Power Transmission Systems", New Age International (P) Ltd., New Delhi, 2002.

[6] Rashid M.H., "Power Electronics Circuits, Devices and Applications ", Prentice Hall India, Third Edition, New Delhi, 2004.

[7] Simple Dynamic Overmodulation Strategy for Fast Torque Control in DTC of Induction Machines With Constant-Switching-Frequency Controller Jidin, A.; Idris, N.R.N.; Yatim, A.H.M.; Sutikno, T.; Elbuluk,
M.E. IEEE Transactions on Industry Applications Year: 2011, Volume: 47, Issue: 5 Pages: 2283 - 2291,

[8] J.Dudrik and N. D. Trip, "Soft-switching PS-PWM DCDC converter for full-load range applications," IEEE Trans. Ind. Electron., vol. 57, no. 8, pp. 2807-2814, Aug. 2010.

[9] K. Raggle, T. Nussbaumer, and J. W. Kolar, "Guideline for a simplified differential-mode EMI filter design," IEEE Trans. Ind. Electron., vol. 57, no. 3, pp. 10311040, Mar. 2010.

[10]Hyungjoon Kim, Changwoo Yoon, and Sewan Choi, IEEE Senior Member Seoul National University of Technology Dept. of Control and Instrumentation Eng. "A three-Phase ZVZCS DC-DC converter for fuel cell applications"

[11] J. G. Cho, J.W. Baek, D.W. Yoo, H. S. Lee, and G. H. Rim, "Novel zerovoltage and zero-current-switching (ZVZCS) full bridge PWM converter using transformer auxiliary winding," in Proc. 28th Annu. IEEE Power Electron. Spec. Conf., (PESC), vol. 1, St. Louis, MO, Jun. 22-27, 1997, pp. 227-232 